\title{
Structural Changes in the Pacific-Japan Pattern in the Late 1990s
}

\author{
Peiqiang Xu, Lin Wang, Wen Chen, Juan Feng, and Yuyun Liu \\ Center for Monsoon System Research, Institute of Atmospheric Physics, Chinese Academy of Sciences, and \\ College of Earth and Planetary Sciences, University of Chinese Academy of Sciences, Beijing, China
}

(Manuscript received 2 March 2018, in final form 14 November 2018)

\begin{abstract}
The Pacific-Japan (PJ) pattern, also known as the East Asia-Pacific pattern, is a teleconnection that significantly influences the East Asian summer climate on various time scales. Based on several reanalysis and observational datasets, this study suggests that the PJ pattern has experienced a distinct three-dimensional structural change in the late 1990s. Compared with those during 1979-98, the PJ pattern shifts eastward by approximately $20^{\circ}$ during 1999-2015, and the intensity of its barotropic structure in the extratropics weakens significantly. As a result, its influences on the summer rainfall along the mei-yu band are weakened after the late 1990s. These observed changes can be attributed to three reasons. First, the location where the PJ pattern is excited shifts eastward. Second, the easterly shear of the background wind is very weak around the source region of the PJ pattern after the late 1990s, which prevents the convection-induced baroclinic mode from converting into barotropic mode and thereby from propagating into the extratropics. Third, the PJ patterninduced rainfall anomalies are weak along the mei-yu band after the late 1990s. As a result, their feedbacks to the PJ pattern become weak and play a considerably reduced role in maintaining the structure of the PJ pattern in the midlatitudes. In contrast, the eddy energy conversion from the basic flow efficiently maintains the PJ pattern before and after the late 1990s and thereby contributes little to the observed change.
\end{abstract}

\section{Introduction}

It has been known for decades that the rainfall anomalies over midlatitude East Asia tend to be opposite of those over the western North Pacific (WNP) on both the intraseasonal and interannual time scales in boreal summer (e.g., Nitta 1986, 1987). When enhanced (suppressed) rainfall is observed over the WNP, suppressed (enhanced) rainfall is often observed along the mei-yu/baiu/changma (mei-yu) rainband stretching from the Yangtze River valley to the south of Japan (Nitta 1987; Huang and Lu 1989; Wang et al. 2001). This seesaw-like pattern, referred to as the Pacific-Japan (PJ) pattern (Nitta 1987) or the East Asia-Pacific (EAP) pattern (Huang and Li 1987), is one of the major teleconnections that alter the rainfall along the mei-yu band, the major rainband over East Asia in boreal summer in both observation (Kosaka et al. 2011; Huang et al. 2012) and climate models (Kosaka and Nakamura 2011; Gong et al. 2018). The PJ/EAP (PJ) pattern consists of two major centers: one is a baroclinic center near the Philippines over the WNP and the other is an equivalent barotropic center

\footnotetext{
Corresponding author: Dr. Lin Wang, wanglin@mail.iap.ac.cn
}

over the midlatitude Far East, the latter of which tilts northward with height (Kosaka and Nakamura 2006). Diagnostic analysis shows that the PJ pattern is a northwardpropagating Rossby wave train in the lower troposphere and an equatorward-propagating Rossby wave train in the upper troposphere (Kosaka and Nakamura 2006), implying its vertical coupling with the Rossby waves emanated from the mid- and high latitudes to the subtropics in the upper troposphere (Hirota and Takahashi 2012).

The formation and maintenance mechanism of the PJ pattern have been an important issue since the discovery of the PJ pattern, and to our knowledge there are three major viewpoints. The first viewpoint regards the PJ pattern as a free Rossby wave train excited by convective activity near the Philippines (Nitta 1987; Huang and Li 1987). This idea is supported by modeling studies with both simple barotropic models (e.g., Kurihara and Tsuyuki 1987) and general circulation models of different hierarchies (e.g., Huang and Li 1987; Nikaidou 1989; Huang and Sun 1992). The variability of the convection near the Philippines and thereby the PJ pattern are suggested to be driven by sea surface temperature (SST) anomalies either locally (Nitta 1987; Huang and Lu 1989) or remotely (Huang and Wu 1989; Zhang et al. 
1996, 1999; Wang et al. 2000; Xie et al. 2009; Kosaka et al. 2013; Xie et al. 2016). The second viewpoint suggests that the PJ pattern can be interpreted as an intrinsic atmospheric dynamical mode inherent in the complicated basic flow over East Asia (Kosaka and Nakamura 2006, 2010) because the structure of the PJ pattern can maintain itself against dissipation through extracting barotropic (Tsuyuki and Kurihara 1989; Lau and Peng 1992) and baroclinic (Kosaka and Nakamura 2006, 2010) energy from the basic flow. The third viewpoint suggests that the latent heat released by mei-yu rainfall acts as a bridge to relay the variability of convection over the WNP to the variability of the PJ pattern in the midlatitudes (Lu and Lin 2009). A simple model experiment indicates that the midlatitude center of the PJ pattern near Japan will be very weak if there are no feedbacks from the mei-yu rainfall (Lu and Lin 2009).

Most of the previous studies focused on the variability of the PJ pattern on intraseasonal and interannual time scales (e.g., Kawamura et al.1996; Yang et al. 2010), whereas the interdecadal variations of the PJ pattern remain less known. On one hand, a regime shift was observed in the East Asian summer monsoon (Huang et al. 2012; Ding et al. 2013; Zhang 2015; Tao et al. 2017; Wang et al. 2017; Wu et al. 2016; Yang et al. 2018) and in the Pacific (Kosaka and Xie 2013; L'Heureux et al. 2013; England et al. 2014; Zhang et al. 2016) since the late 1990s, implying possible interdecadal changes of the PJ pattern. On the other hand, the structure of certain atmospheric patterns may experience significant changes in association with a shift of the climate regime (e.g., Wang et al. 2007, 2010; Lin et al. 2017). Therefore, it is interesting to investigate whether the structure of the PJ pattern experiences interdecadal changes in the late 1990s and, if so, what is the possible reason. These two issues will be addressed in this paper. Section 2 describes the datasets and methods used in this study. Section 3 presents evidence that the PJ pattern shows clear structural change both horizontally and vertically in the late 1990s, and section 4 discusses the possible mechanism that is responsible for this observed change. Finally, section 5 summarizes the main findings and section 6 provides further discussions.

\section{Data and methods}

Monthly mean atmospheric reanalysis data used in this study are from the National Centers for Environment Prediction-Department of Energy (NCEPDOE) Atmospheric Model Intercomparison Project-II reanalysis dataset (Kanamitsu et al. 2002), which has a horizontal resolution of $2.5^{\circ} \times 2.5^{\circ}$ and spans the period 1979-2015. The ERA-Interim dataset (Dee et al. 2011) from the European Centre for Medium-Range Weather
Forecasts was also used to check whether the results reported in this study are sensitive to the choice of dataset, and the results suggest that using different datasets yield the same conclusion (not shown). Therefore, the results obtained only from the ERA-Interim dataset are shown. Monthly mean precipitation data are from the Global Precipitation Climatology Project (GPCP) dataset with a $2.5^{\circ} \times 2.5^{\circ}$ resolution for the period 1979-2015 (Adler et al. 2003). The interpolated monthly mean outgoing longwave radiation $(\mathrm{OLR})$ data on $2.5^{\circ} \times 2.5^{\circ}$ grids for the period 1979-2015, provided by the National Oceanic and Atmospheric Administration (NOAA), are used as a proxy for convection (Liebmann and Smith 1996). The oceanic data are from the Hadley Centre Sea Ice and Sea Surface Temperature (HadISST) dataset (Rayner et al. 2003).

This study focuses on the boreal summer, defined as the mean of June-August. Following Kosaka and Nakamura (2010), the PJ pattern is defined as the first empirical orthogonal function (EOF) of the summer mean $850-\mathrm{hPa}$ relative vorticity field over East Asia $\left(0^{\circ}-60^{\circ} \mathrm{N}, 100^{\circ}-\right.$ $160^{\circ} \mathrm{E}$ ), and the $\mathrm{PJ}$ index is defined as the normalized first principal component (PC) time series. Meteorological variables linearly regressed onto the $\mathrm{PJ}$ index are used to indicate the PJ pattern-related meteorological fields. The two-tailed Student's $t$ test is used to evaluate the confidence level of linear correlation and regression.

\section{Observed structural changes of the $\mathbf{P J}$ pattern}

Figure 1a presents the spatial pattern of the first EOF (EOF1) of the summer mean 850-hPa relatively vorticity field over East Asia $\left(0^{\circ}-60^{\circ} \mathrm{N}, 100^{\circ}-160^{\circ} \mathrm{E}\right)$ during 1979-2015, which explains $17.1 \%$ of the total variance and is well separated from the remaining modes according to the criteria of North et al. (1982). The pattern is zonally elongated and extends meridionally from the tropics to north of Japan. Corresponding to the positive phase of the first PC (PC1) time series (Fig. 1b), an anomalous anticyclonic center is observed over the WNP at approximately $15^{\circ} \mathrm{N}$ and an anomalous cyclonic center is observed over the midlatitudes of East Asia at approximately $30^{\circ} \mathrm{N}$ (Fig. 1a). In addition, a weak cyclonic center is also observed over the Sea of Okhotsk, implying the northward propagation of Rossby wave train into high latitudes along the coast of East Asia in the lower troposphere. All these features resemble the typical PJ pattern (Nitta 1987; Kosaka and Nakamura 2006). Hereafter, the pattern in Fig. 1a and the time series in Fig. 1b are called the PJ pattern and the PJ index, respectively.

\section{a. Eastward shift of the PJ pattern after the late 1990s}

To depict the possible structural changes of the PJ pattern in the late 1990s, the period 1979-2015 is divided 
(a) EOF1

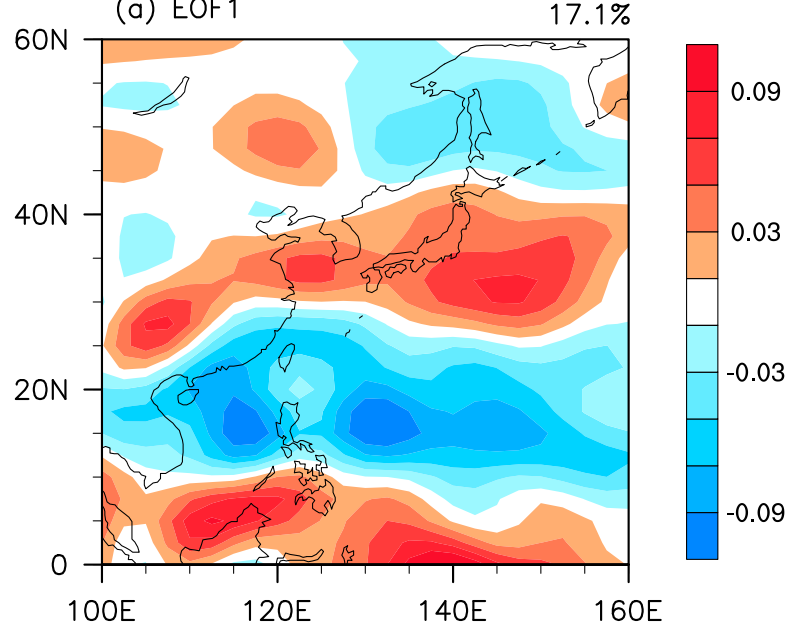

(b) PC1

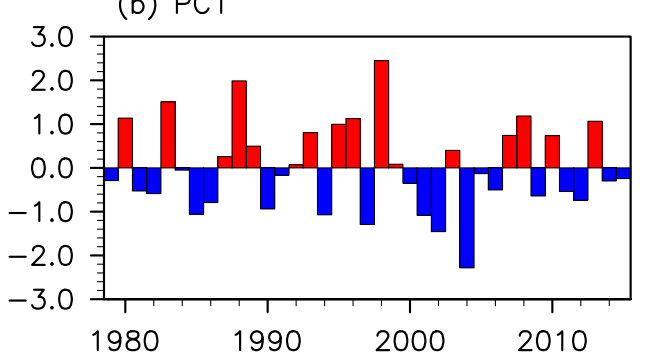

FIG. 1. (a) EOF1 pattern of the summer mean $850-\mathrm{hPa}$ relative vorticity over the $\mathrm{WNP}\left(0^{\circ}-60^{\circ} \mathrm{N}, 100^{\circ}-160^{\circ} \mathrm{E}\right)$ for the period 1979 2015. The variance explained by EOF1 is indicated in the upperright corner. (b) The corresponding normalized PC1 time series (i.e., the PJ index).

into two subperiods - the preperiod (1979-98) and the postperiod (1999-2015) — and various variables are then regressed onto the PJ index during the two subperiods. Figure 2a shows the PJ pattern-related 850-hPa relative vorticity pattern in the preperiod. It is characterized by the zonally elongated centers with alternating signs, which quite resemble the PJ pattern obtained from the period 1979-2015 (Fig. 1a). The maximum of the anticyclonic center near the Philippines is located west of $140^{\circ} \mathrm{E}$, and the maximum of the cyclonic center over the midlatitudes is located southeast of Japan (Fig. 2a). The wave activity flux (Takaya and Nakamura 2001) of the PJ pattern emanates from regions surrounding the Philippine Islands and points northeastward toward the cyclonic center near Japan, confirming the Rossby wave nature of the PJ pattern (Nitta 1987). In the postperiod, in contrast, a similar wavelike pattern can still be observed over the WNP, but the pattern shifts eastward (Fig. 2c). Especially, the maximum of the anticyclonic center near the Philippines shifts from west of $140^{\circ} \mathrm{E}$ in the preperiod to east of $140^{\circ} \mathrm{E}$ in the postperiod by approximately $20^{\circ}$. The cyclonic center near Japan and the anticyclonic center over the Sea of Okhotsk also shift eastward by approximately $10^{\circ}$. In addition to circulations, the eastward shift of the PJ pattern can be recognized from the wave activity fluxes between $10^{\circ}$ and $30^{\circ} \mathrm{N}$ (Figs. 2a,c). These results suggest that the PJ pattern-related lower-tropospheric circulation pattern experiences a distinct eastward shift in the late 1990s.

The variability of the PJ pattern is related to the summer rainfall over East Asia and the WNP (Kosaka et al. 2011), so the eastward shift of the PJ pattern is expected to have some embodiment in the rainfall. Figure 3 presents the summer mean OLR and rainfall in the two subperiods corresponding to the positive phase of the PJ pattern. In both periods the PJ pattern is closely related to the convection activity and rainfall around the Philippines, and the Philippine convection and rainfall anomalies associated with one standard deviation of the PJ pattern locally account for more than $20 \%$ of their respective climatological magnitudes. In the preperiod, suppressed convection (Fig. 3a) and rainfall (Fig. 3b) are observed over the WNP $\left(10^{\circ}-20^{\circ} \mathrm{N}\right.$, $110^{\circ}-160^{\circ} \mathrm{E}$ ), with the minimum center being located between $130^{\circ}$ and $140^{\circ} \mathrm{E}$, and enhanced convection and precipitation are observed over the lower reaches of the Yangtze River valley and southeast of Japan (Figs. 3a,b). In addition, suppressed convection and reduced rainfall can also be observed at high latitudes near the Sea of Okhotsk. All these features resemble those reported in previous studies (e.g., Kosaka and Nakamura 2006). In the postperiod, in contrast, both the suppressed convection (Fig. 3c) and rainfall (Fig. 3d) at the subtropics shift eastward. The minimum center east of the Philippines shifts from approximately $130^{\circ} \mathrm{E}$ in the preperiod to approximately $150^{\circ} \mathrm{E}$ in the postperiod. In addition, the center of enhanced convection and rainfall near Japan also shifts eastward and shrinks, and the signals of convection and rainfall over the lower reaches of the Yangtze River valley almost disappear. These results suggest an eastward shift of the PJ pattern-related rainfall anomalies at midlatitudes and thereby weakened influences of the PJ pattern on the summer rainfall over eastern China in the postperiod. The changes in rainfall and convection are in alignment with those shown in the lower-tropospheric circulation (Figs. 2a,c). Therefore, it is reasonable to conclude that the $\mathrm{PJ}$ pattern shifts eastward significantly in the late 1990s.

\section{b. Weakened vertical coupling of the PJ pattern after the late 1990s}

Traditional studies regard the PJ pattern as a free Rossby wave train propagating from the subtropics to 

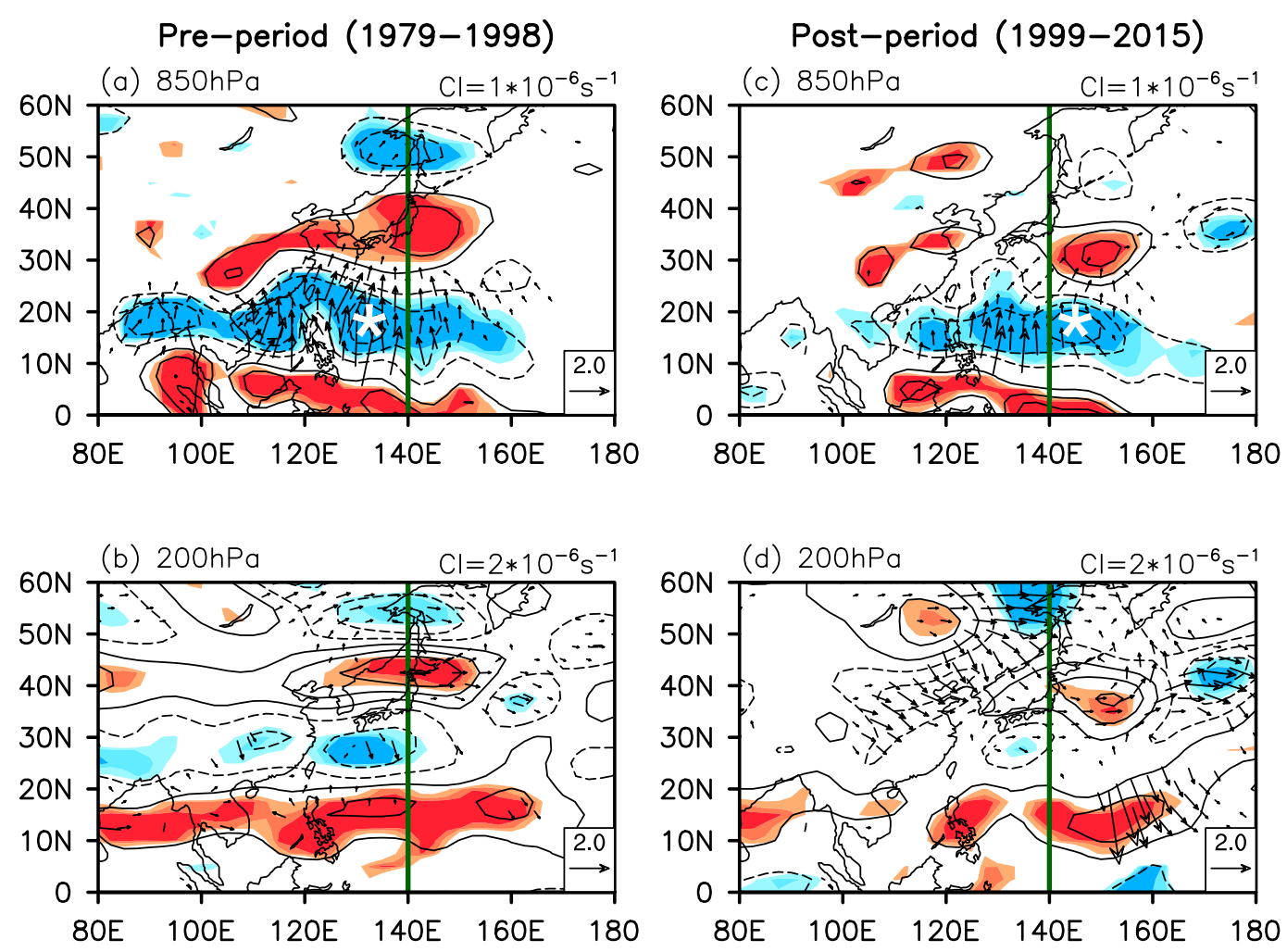

FIG. 2. The summer mean relative vorticity (contour) and the associated wave activity flux (arrow; $\mathrm{m}^{2} \mathrm{~s}^{-2}$ ) at (a) 850 and (b) $200 \mathrm{hPa}$ regressed onto the normalized PJ index during the preperiod. (c),(d) As in (a) and (b), respectively, but for the postperiod. Contour intervals (CIs) are $1 \times 10^{-6} \mathrm{~s}^{-1}$ in (a) and (c), and $2 \times 10^{-6} \mathrm{~s}^{-1}$ in (b) and (d). The three shadings indicate the $90 \%, 95 \%$, and $98 \%$ confidence levels, respectively, based on a twotailed Student's $t$ test. The vertical lines indicate $140^{\circ} \mathrm{E}$, and the stars indicate the maxima location in the respective subtropical action centers at $850 \mathrm{hPa}$.

the mid- and high latitudes in the lower troposphere (Nitta 1987; Huang and Li 1987). Recent studies suggest that this lower-tropospheric wave train shows a northwardtilted structure in the extratropics, and it is strongly coupled to a southward-propagating Rossby wave train from the mid- and high latitudes to the subtropics in the upper troposphere (Kosaka and Nakamura 2006; Hirota and Takahashi 2012). Considering a distinct eastward shift of the lower-tropospheric PJ pattern was observed after the late 1990s (section 3a), it is interesting to examine whether the vertical structure of the PJ pattern changed in the late 1990s.

Figure $2 \mathrm{~b}$ shows the PJ pattern-related 200-hPa relative vorticity pattern in the preperiod. Zonally elongated centers with alternating signs are observed along the coast of East Asia, and the associated wave activity fluxes indicate southward Rossby wave propagation between approximately $15^{\circ}$ and $35^{\circ} \mathrm{N}$. Nevertheless, the wave activity fluxes in the upper troposphere (Fig. 2b) are weaker than those in the lower troposphere (Fig. 2a) despite the well-organized relative vorticity patterns (Fig. 2b). All these features are consistent with Kosaka and Nakamura (2006). In the postperiod, in contrast, the meridionally oriented relatively vorticity pattern in the upper troposphere is not well organized (Fig. 2d). A northwest-southeast-oriented wavelike pattern is observed north of $20^{\circ} \mathrm{N}$, and the cyclonic center between $10^{\circ}$ and $20^{\circ} \mathrm{N}$ shifts eastward slightly, consistent with its lower-tropospheric counterpart. Recall that the relative vorticity fields in the upper troposphere are obtained by regressions onto the $\mathrm{PJ}$ index, the $\mathrm{PC} 1$ time series of the EOF1 of the 850-hPa vorticity field. Hence, it is inferred that the PJ pattern-related vertical coupling between the lower and upper troposphere is weakened after the late 1990s.

To confirm the aforementioned inference, the vertical structure of the PJ pattern is further examined. Figure 4 shows the latitude-altitude section of PJ pattern-related relative vorticity averaged over the longitude band $\left(110^{\circ}-150^{\circ} \mathrm{E}\right)$ where the main body of the PJ pattern is located. In the preperiod, the PJ pattern features a baroclinic structure between $10^{\circ}$ and $20^{\circ} \mathrm{N}$ and an equivalent barotropic structure north of $20^{\circ} \mathrm{N}$ (Fig. 4a). The well-organized extratropical barotropic structure slightly tilts northward with height, facilitating the 

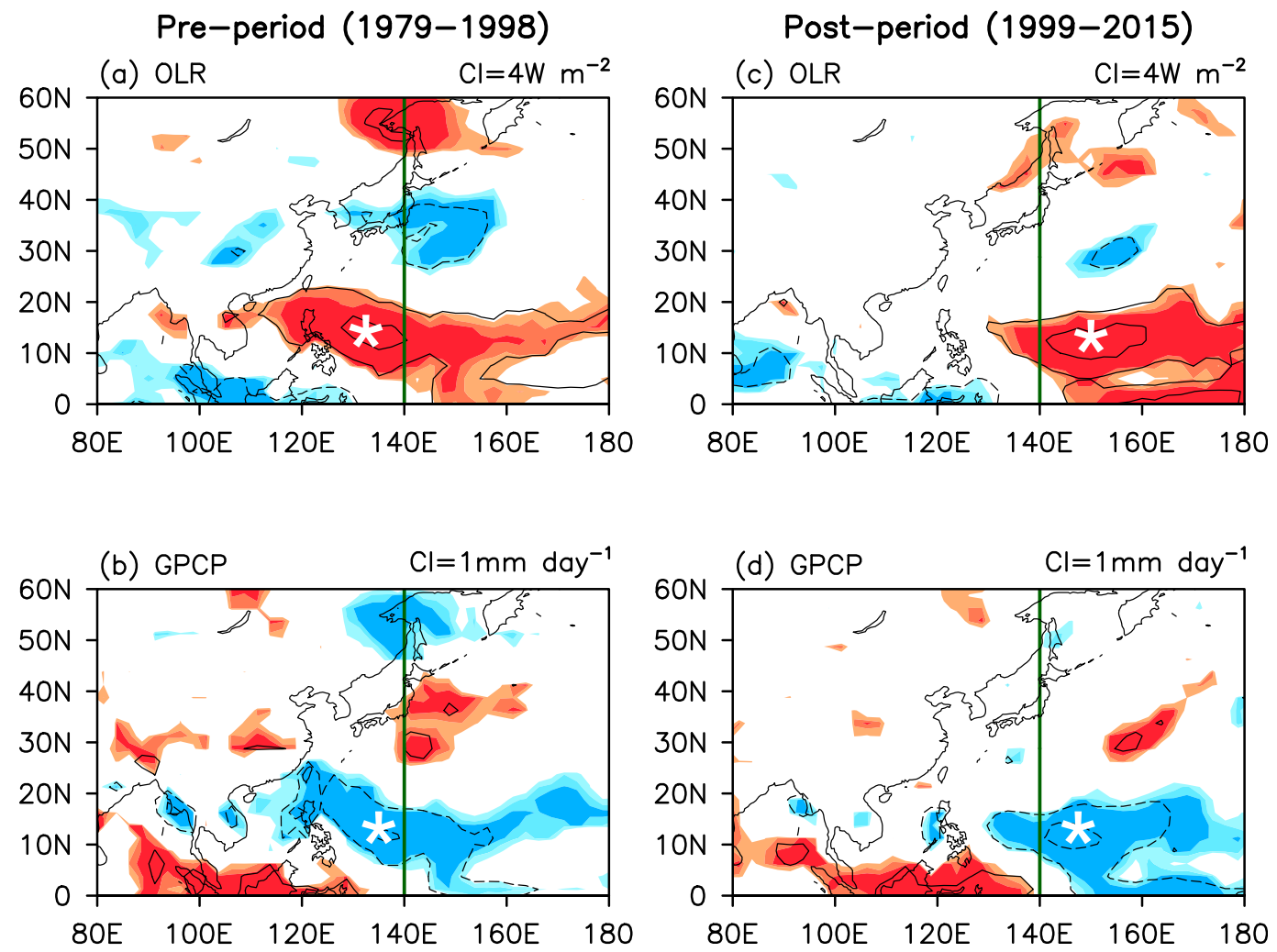

FIG. 3. The summer mean (a) OLR (CI $\left.=4 \mathrm{~W} \mathrm{~m}^{-2}\right)$ and (b) GPCP rainfall ( $\left.\mathrm{CI}=1 \mathrm{~mm} \mathrm{day}^{-1}\right)$ regressed onto the normalized PJ index during the preperiod. (c),(d) As in (a) and (b), respectively, but for the postperiod. The three shadings indicate the $90 \%, 95 \%$, and $98 \%$ confidence levels, respectively, based on a two-tailed Student's $t$ test. The vertical line in each panel indicates $140^{\circ} \mathrm{E}$, and the stars indicate the maxima location in the respective subtropical action centers.

extraction of baroclinic energy from the basic flow via zonal eddy heat flux (Kosaka and Nakamura 2006). All these characteristics are consistent with those reported in Kosaka and Nakamura (2006). In the postperiod, in contrast, though the amplitude is weakened slightly, the baroclinic structure of the PJ pattern in the subtropics remains almost the same. However, the barotropic structures of the PJ pattern in the extratropics vanishes greatly (Fig. 4b), and only some weak cyclonic anomalies can be observed near $35^{\circ} \mathrm{N}$ in the lower troposphere (Fig. 4b), consistent with those shown in Fig. 2. This remarkable difference confirms that the PJ pattern-related vertical coupling between the lower and upper troposphere in the extratropics is significantly weakened after the late 1990s.

\section{Possible mechanism}

\section{a. Role of convection near the Philippines}

As reviewed in section 1 , the $\mathrm{PJ}$ pattern is traditionally regarded as a free Rossby wave train excited and emanated from the subtropical WNP (Nitta 1987; Huang and
Li 1987). Hence, the first candidate to explain the observed structural changes of the PJ pattern is the changes of the Rossby wave source (RWS) over the subtropical WNP. Figure 5 presents the PJ pattern-related RWS (Sardeshmukh and Hoskins 1988) in the pre- and postperiods. In the preperiod, significant anticyclonic and cyclonic RWS are observed over the subtropical WNP (approximately $15^{\circ}-25^{\circ} \mathrm{N}, 120^{\circ}-160^{\circ} \mathrm{E}$ ) in the lower (Fig. 5a) and upper (Fig. 5b) troposphere, respectively. This baroclinic RWS is consistent with the baroclinic structure of the PJ pattern (Figs. 2a,b), and it indicates the baroclinic response of the atmosphere to convective perturbations over the Philippine Sea (Figs. 3a,b). The centers of the RWS are located near $15^{\circ} \mathrm{N}, 135^{\circ} \mathrm{E}$ in both the lower and upper troposphere, and the main body of the anticyclonic (cyclonic) RWS signals in the lower (upper) troposphere is located to the west of $140^{\circ} \mathrm{E}$ (Figs. 2a,b). In the postperiod, however, the RWS over the subtropical WNP between $120^{\circ}$ and $140^{\circ} \mathrm{E}$ in both the lower (Fig. 5c) and upper (Fig. 5d) troposphere shifts to the east of $140^{\circ} \mathrm{E}$. The eastward shift of the RWS in the postperiod is consistent with the 

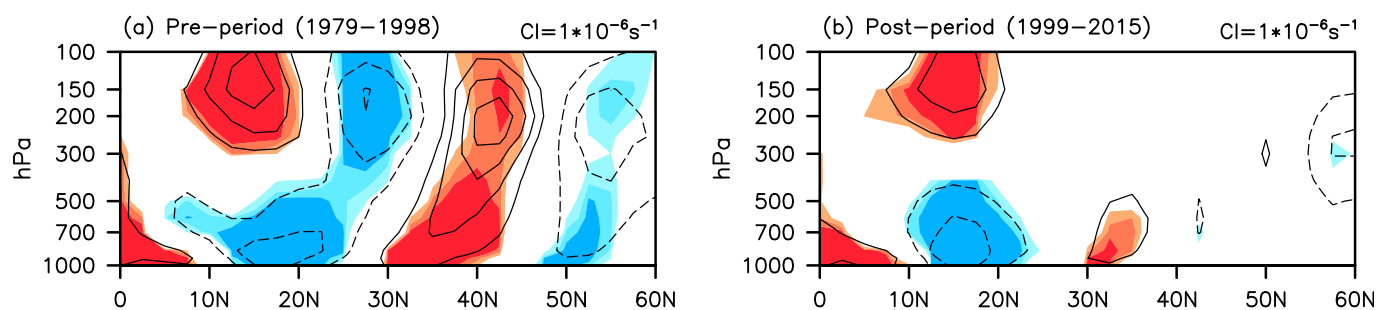

FIG. 4. As in Figs. 2a and 2c, but for the summer mean relative vorticity averaged between $110^{\circ}$ and $150^{\circ} \mathrm{E}$.

eastward shift of the PJ pattern-related convection/ rainfall and thereby diabatic heating over the WNP (Fig. 3). Hence, these results suggest that the location where the PJ pattern is excited shifts eastward after the late 1990s, and this is very likely the direct cause of the eastward shift of the PJ pattern.

The eastward shift of PJ pattern-related RWS, convection, and rainfall around the Philippines after the late 1990s is also associated with the eastward movement of the climatological variability center of convection. Figure 6 shows the standard deviation, which is used to measure the strength of interannual variability, of the summer mean convection and rainfall in the preperiod and postperiod. In the preperiod, the variability of both the OLR (Fig. 6a) and rainfall (Fig. 6b) shows maximum centers over approximately $\left(10^{\circ}-20^{\circ} \mathrm{N}, 120^{\circ}-140^{\circ} \mathrm{E}\right)$. The variability of the OLR also shows a second maximum center over approximately $\left(10^{\circ}-20^{\circ} \mathrm{N}, 140^{\circ}-170^{\circ} \mathrm{E}\right)$ (Fig. 6a), but a similar center is not observed for rainfall (Fig. 6b). The consistency in OLR and the rainfall field suggests that the place where the diabatic heating is most active on the interannual time scale is located over $\left(10^{\circ}-20^{\circ} \mathrm{N}, 120^{\circ}-140^{\circ} \mathrm{E}\right)$ in the preperiod. In the postperiod, the maximum centers of variability significantly weaken and even disappear for both OLR (Fig. 6c) and rainfall (Fig. 6d) over $\left(10^{\circ}-20^{\circ} \mathrm{N}\right.$, $120^{\circ}-140^{\circ} \mathrm{E}$ ), whereas consistent maximum centers are observed over $\left(10^{\circ}-20^{\circ} \mathrm{N}, 140^{\circ}-160^{\circ} \mathrm{E}\right)$. This result suggests that the place where the diabatic heating is most active on the interannual time scale shifts eastward (or is

\section{Pre-period (1979-1998)}

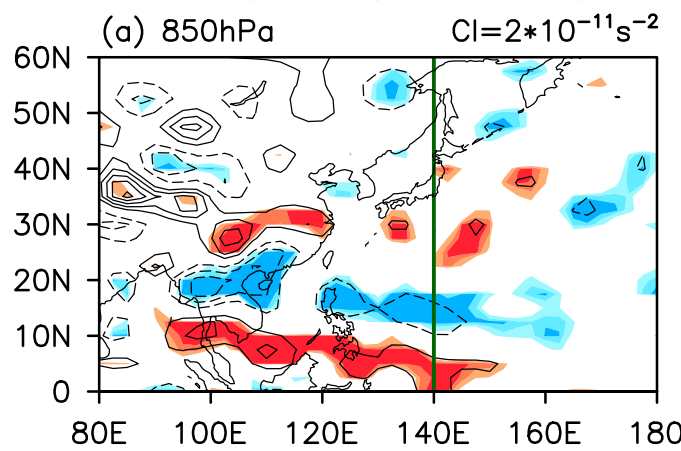

Post-period (1999-2015)

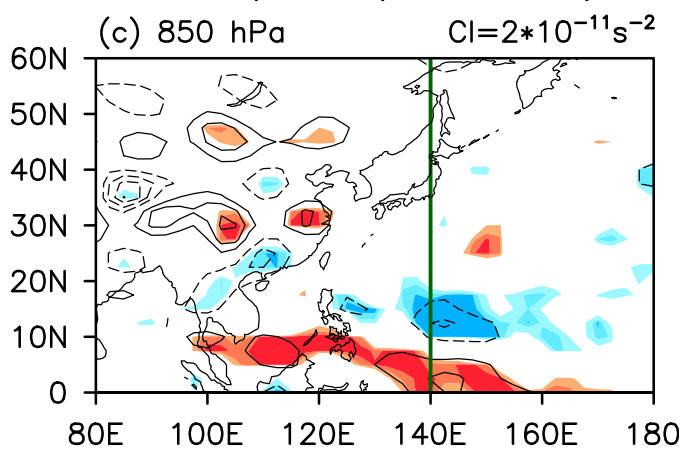

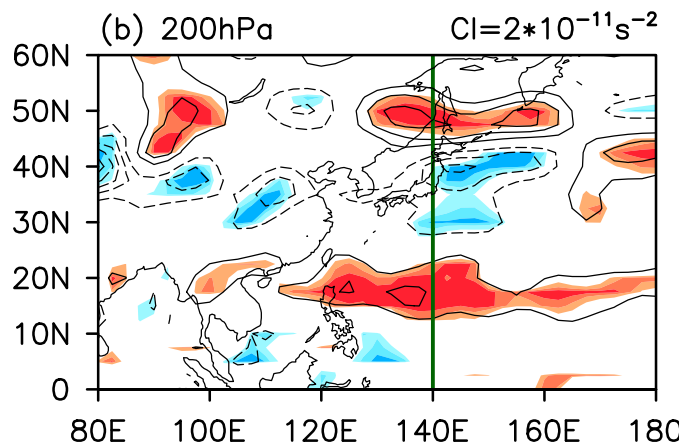

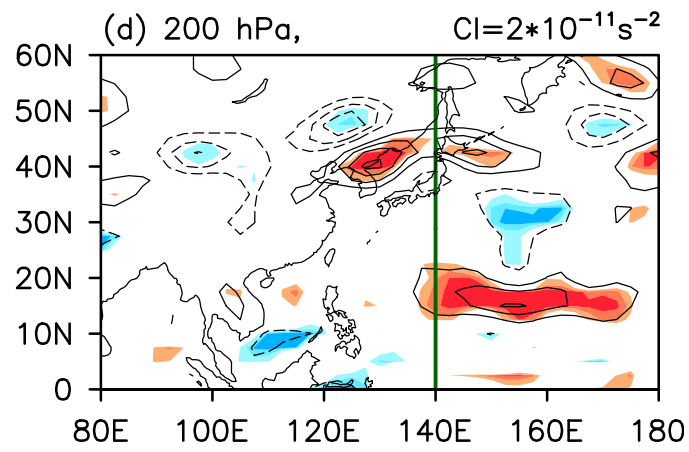

FIG. 5. As in Fig. 2, but for the RWS (CI $\left.=2 \times 10^{-11} \mathrm{~s}^{-2}\right)$ at 850 and $200 \mathrm{hPa}$. 
Pre-period (1979-1998)

(a) OLR

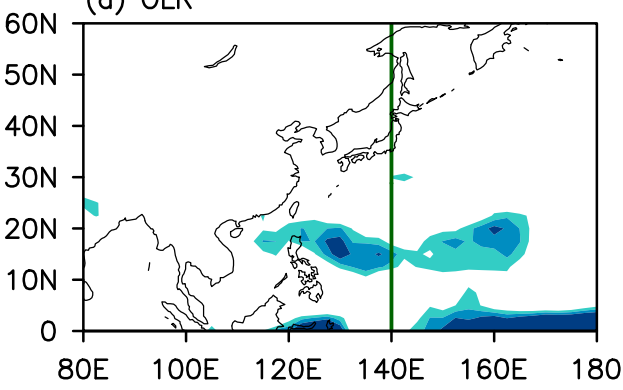

Post-period (1999-2015)

(c) OLR

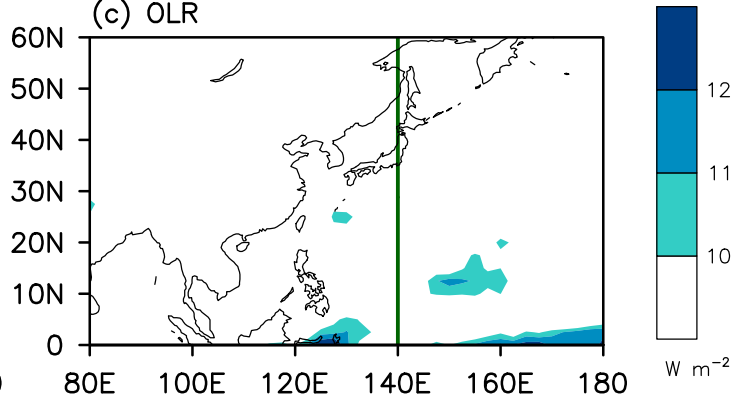

(b) GPCP

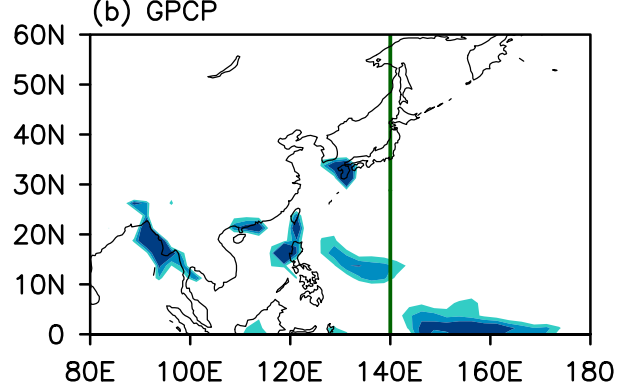

(d) GPCP

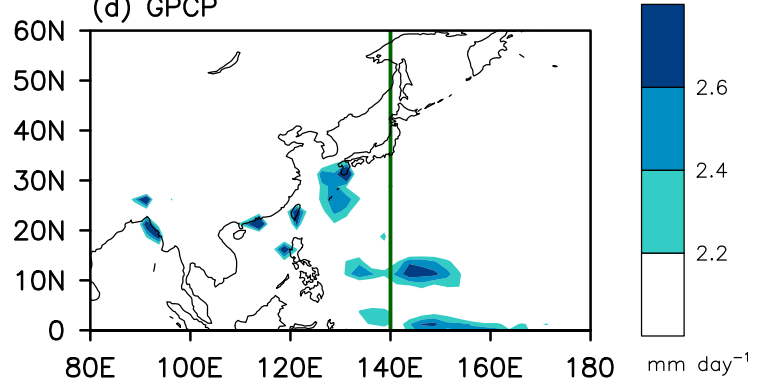

FIG. 6. The interannual standard deviation of the summer mean (a) OLR [shading interval (SI) $=1 \mathrm{~W} \mathrm{~m}^{-2}$ ] and (b) GPCP rainfall (SI $=0.2 \mathrm{~mm} \mathrm{day}^{-1}$ ) during the preperiod. (c),(d) As in (a) and (b), respectively, but for the postperiod. The vertical line in each panel indicates $140^{\circ} \mathrm{E}$.

more concentrated on the eastern side) in the postperiod. A comparison between Figs. 6 and 3 suggests that the region with the most active convection and rainfall (and thereby diabatic heating) over the subtropical WNP (Fig. 6) coincides with the center of $\mathrm{PJ}$ pattern-related convection and rainfall (Fig. 3) in both subperiods. Therefore, the observations indicate that the shift of the PJ pattern-related convection around the Philippines, which is suggested to be the direct cause of the eastward shift of the PJ pattern in the postperiod, is a very robust phenomenon that even manifests itself in the climatology. Further discussion regarding why the climatological variability center of convection in the tropics shifts eastward is presented in section 6 .

\section{b. Role of the vertical shear of the background zonal wind}

From this subsection on, the reason that leads to changes in the vertical structure of the $\mathrm{PJ}$ pattern in the extratropics will be explored. Although the subtropical convection that could excite the PJ pattern over the Philippine Sea shifts eastward in the postperiod, the intensity of the PJ patternrelated convection anomalies remains almost the same (Fig. 3), implying that the diabatic heating necessary to excite the PJ pattern does not change much. Therefore, the PJ pattern-related RWS over the Philippine Sea remains of similar magnitude (Fig. 5), and the baroclinic structure of the PJ pattern between $10^{\circ}$ and $20^{\circ} \mathrm{N}$ is both well-established with similar intensity in both subperiods (Fig. 4). In this circumstance, the weak extratropical anomaly of the PJ pattern in the postperiod implies that the PJ pattern-related disturbances are possibly trapped within the tropics by climatological-mean flow.

It is well known that the convection-induced latent heating over the Philippine Sea usually maximizes in the midtroposphere in boreal summer, and this heating is able only to excite baroclinic disturbances that are trapped within the tropics (e.g., Lu 2004). To convey the thermally induced baroclinic disturbances to the extratropics, the baroclinic structure must be converted into a barotropic structure around the source region (Kosaka and Nakamura 2006). In this process, the easterly shear of background zonal flow is very important for the conversion (Kasahara and da Silva Dias 1986; Lim and Chang 1986; Kato and Matsuda 1992; Wang and Xie 1996), and this mechanism has been proved to be important to explain the structure of the PJ pattern in different summer months (Lu 2004). Here, we will show that this mechanism can also explain the different extratropical structure of the PJ pattern in the two subperiods.

Figure 7 shows the vertical profile of the areaaveraged summer mean zonal wind over the source region of the PJ pattern. In the preperiod, the region $\left(10^{\circ}-20^{\circ} \mathrm{N}, 100^{\circ}-160^{\circ} \mathrm{E}\right)$ is examined because it is where the subtropical center of the PJ pattern is excited 


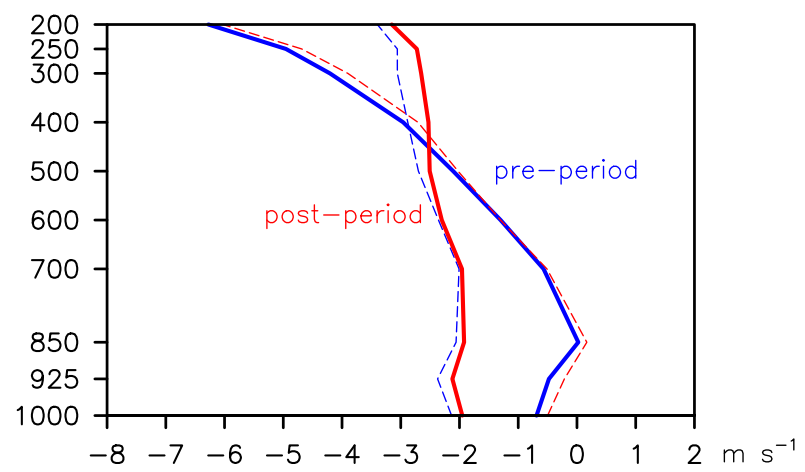

FIG. 7. Vertical profile of the summer mean zonal wind $\left(\mathrm{m} \mathrm{s}^{-1}\right)$ averaged over the region $\left(10^{\circ}-20^{\circ} \mathrm{N}, 100^{\circ}-160^{\circ} \mathrm{E}\right)$ for the preperiod (blue solid line) and over the region $\left(10^{\circ}-20^{\circ} \mathrm{N}, 110^{\circ}-170^{\circ} \mathrm{E}\right)$ for the postperiod (red solid line). The dashed lines indicate the vertical profile of zonal wind averaged over the region $\left(10^{\circ}-20^{\circ} \mathrm{N}, 110^{\circ}-\right.$ $170^{\circ} \mathrm{E}$ ) in the preperiod (blue dashed line) and over the region $\left(10^{\circ}-20^{\circ} \mathrm{N}, 100^{\circ}-160^{\circ} \mathrm{E}\right)$ in the postperiod (red dashed line).

(Figs. 3a,b). This region is also the same as that used in $\mathrm{Lu}$ (2004). Strong easterly shear is observed in this region, and it provides a favorable environment for the conversion of baroclinic disturbances into barotropic ones. As a result, the convection-induced disturbances are able to propagate into midlatitudes with an equivalent barotropic structure (Fig. 4a). In the postperiod, however, the easterly shear is very weak around the source region of the PJ pattern (Fig. 7), indicating the baroclinic-barotropic coupling process is inhibited at this time. Therefore, the convection-induced disturbances are largely trapped south of $20^{\circ} \mathrm{N}$ (Fig. 4b) as a result of the small baroclinic Rossby deformation radius. Note in the postperiod the region $\left(10^{\circ}-20^{\circ} \mathrm{N}\right.$, $110^{\circ}-170^{\circ} \mathrm{E}$ ) is used to calculate the vertical shear. This region overall shifts $10^{\circ}$ eastward compared to the preperiod, in accordance with the eastward shift of the PJ pattern-related convection activity around the Philippines. The changes of the vertical shear is mainly caused by the eastward shift of the PJ pattern (Fig. 7). These results suggest that both Philippine convection activity and largescale environmental flow play essential roles in the full buildup of the PJ pattern, whose nature could be interpreted as the Rossby wave train. The convection activity around the Philippines acts as external forcing and could affect the wave source associated with the PJ pattern. In contrast, the atmospheric basic flow could exert a profound influence on the propagation of Rossby wave and wavemean flow interactions associated with the PJ pattern. The three-dimensional structure of the PJ pattern will not organize coherently like that in the preperiod if either of the aforementioned two factors is weak or not present.

In addition to the vertical shear of zonal wind, the vertical shear of the meridional wind is also an essential factor for the formation of the PJ pattern (Kawamura et al. 1996; Kosaka and Nakamura 2006). The vertical shear of the meridional wind during the two subperiods, however, is quite similar (not shown), indicating its negligible contribution to the weakened vertical coupling of the PJ pattern after the late 1990s.

\section{c. Role of the feedbacks from mei-yu rainfall}

As reviewed in section 1, the third mechanism of the formation of the PJ pattern emphasizes the feedbacks of mei-yu rainfall (Lu and Lin 2009). An inspection of Fig. 3 indicates that the rainfall and convection anomalies associated with the PJ pattern along the mei-yu band $\left(30^{\circ}-40^{\circ} \mathrm{N}, 100^{\circ}-160^{\circ} \mathrm{E}\right)$ weaken considerably in the postperiod. The upper-tropospheric RWS field along the mei-yu band also confirms this change (Fig. 5). In this circumstance, the reduced rainfall anomaly along the mei-yu band in the postperiod will lead to weakened feedbacks to circulation ( $\mathrm{Lu}$ and Lin 2009), and it is unable to relay the variability of convection activity around the Philippines to the PJ pattern in the midlatitudes. This process may also contribute to the significant weakening of the barotropic anomaly of the PJ pattern north of $20^{\circ} \mathrm{N}$.

One natural question is why the PJ pattern-related precipitation anomaly along the mei-yu band is weakened in the postperiod. This question is difficult to answer ultimately because the variations of mei-yu rainfall on the interannual time scale involves self-maintained feedbacks between rainfall and circulation (Kosaka et al. 2011). However, it can be addressed to some extent by examining the linearized quasigeostrophic $(\mathrm{QG})$ omega equation. Under the QG approximation, the vertical motion can be induced by three major processes: the vertical difference of horizontal vorticity advection, the Laplacian of horizontal temperature advection, and the Laplacian of diabatic heating (Holton 2004; Kosaka et al. 2011; Hu et al. 2017; Gu et al. 2018), which is defined as follows:

$$
\begin{aligned}
\omega^{\prime}= & \left(\nabla^{2}+\frac{f^{2}}{\sigma} \frac{\partial^{2}}{\partial p^{2}}\right)^{-1} \frac{f}{\sigma} \frac{\partial}{\partial p}\left[\bar{v} \cdot \nabla \zeta^{\prime}+v^{\prime} \cdot \nabla(f+\bar{\zeta})\right] \\
& +\left(\nabla^{2}+\frac{f^{2}}{\sigma} \frac{\partial^{2}}{\partial p^{2}}\right)^{-1} \frac{R}{\sigma p} \nabla^{2}\left(\bar{v} \cdot \nabla T^{\prime}+v^{\prime} \cdot \nabla \bar{T}\right) \\
& -\left(\nabla^{2}+\frac{f^{2}}{\sigma} \frac{\partial^{2}}{\partial p^{2}}\right)^{-1} \frac{R}{\sigma p} \nabla^{2} Q^{\prime}
\end{aligned}
$$

where all operators and variables are of conventional usage in meteorology. The QG omega equation has been used in previous studies to diagnose the vertical motion over the main rain belts of East Asia (Kosaka et al. 2011; Gu et al. 2018). In solving Eq. (1), $\omega^{\prime}$ is set to 

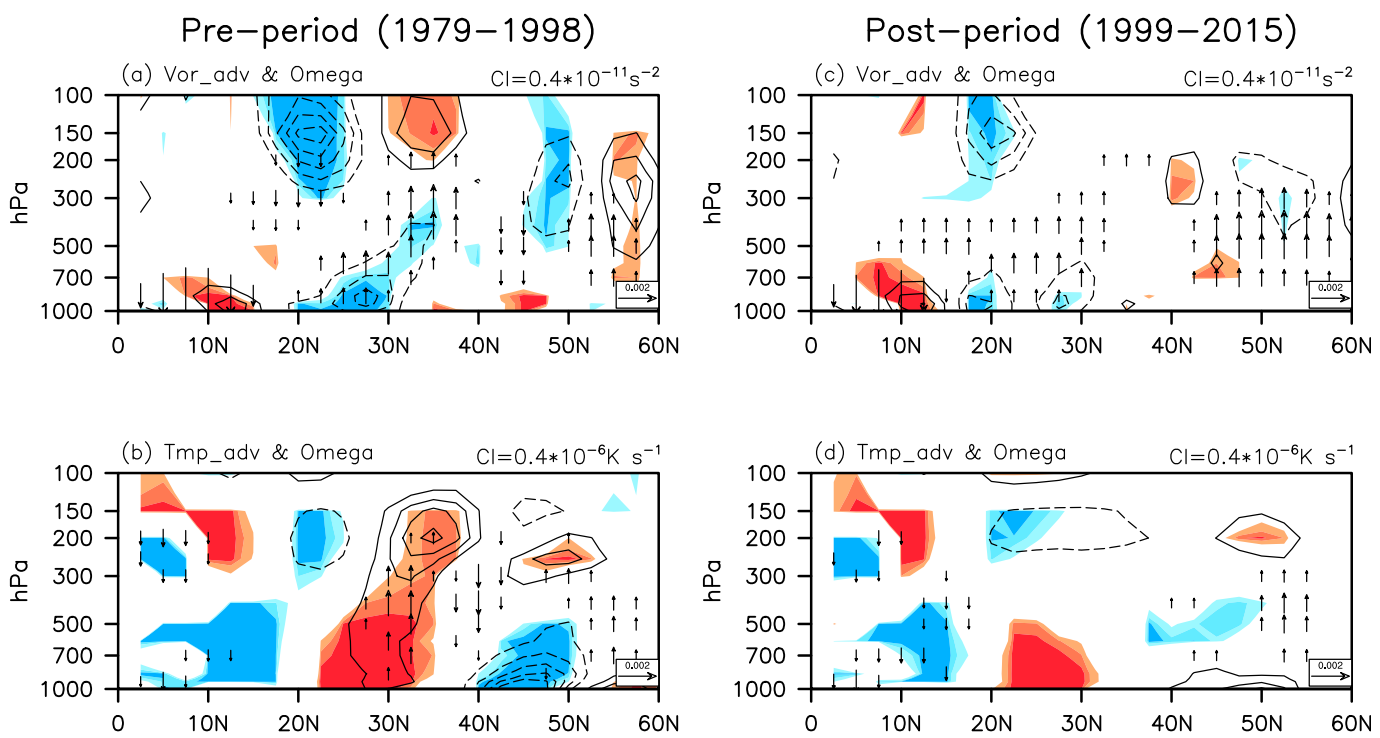

FIG. 8. (a) The $100^{\circ}-150^{\circ} \mathrm{E}$ averaged summer mean PJ pattern-related vorticity advection (contour; $\mathrm{CI}=0.4 \times$ $10^{-11} \mathrm{~s}^{-2}$ ) and associated forced vertical velocity (arrow; $\mathrm{Pa} \mathrm{s}^{-1}$ ) by solving the QG omega Eq. (1) during the preperiod. (b) As in (a), but for the temperature advection (contour; $\mathrm{CI}=0.4 \times 10^{-6} \mathrm{~K} \mathrm{~s}^{-1}$ ) and the associated forced vertical velocity (arrow). (c),(d) As in (a) and (b), respectively, but for the postperiod. The vertical velocity is multiplied by -1 for visual purposes. The three shadings indicate the $90 \%, 95 \%$, and $98 \%$ confidence levels, respectively, based on a two-tailed Student's $t$ test.

be zero along the lateral boundaries and at the bottom $(1000 \mathrm{hPa})$ and top $(70 \mathrm{hPa})$ boundaries. The calculated vertical velocity by solving Eq. (1) with full forcing on the right-hand side shows comparable magnitude and a similar spatial pattern to the observed anomalies, especially along the mei-yu rain belt, suggesting the QG omega equation provides a good approximation to the vertical motion in the reanalysis. To investigate the different causes of mei-yu rainfall anomalies in the two subperiods, following Kosaka et al. (2011), only the effect of dry dynamics (i.e., the first two processes related to vorticity and temperature advection) is considered, whereas the effect of moist diabatic heating is excluded because there are strong interactions between rainfall and circulation along the mei-yu band (Sampe and Xie 2010; Kosaka et al. 2011).

Figure 8 presents the latitude-altitude section of the PJ pattern-related vorticity advection (contour in the upper panel), temperature advection (contour in the lower panel), and the vertical velocity (arrow) by solving Eq. (1) with either the vorticity forcing or the thermal forcing only. Here the vertical velocity has been multiplied by -1 for visual purposes. For simplicity, only the anomalous vorticity advection $-\overline{\boldsymbol{v}}_{g}\left(\partial \zeta_{g}^{\prime} / \partial y\right)$ and temperature advection $-u_{g}^{\prime}(\partial \bar{T} / \partial x)$ are drawn because these are the dominant terms responsible for the vertical motion along the mei-yu band (Zhao et al. 2015), while the forced vertical motion is calculated by solving the full version of Eq. (1). In the preperiod, the anomalous vorticity advection term is positive in the upper troposphere and negative in the lower troposphere at approximately $35^{\circ} \mathrm{N}$ (Fig. 8a), where the climatological latitude of mei-yu band is located, and anomalous temperature advection is positive at the same latitude throughout the troposphere with maxima in the upper troposphere (Fig. 8b). These configurations create strong vertical difference of horizontal vorticity advection and strong Laplacian of horizontal temperature advection along the mei-yu band. As a result, enhanced upward motion is generated to keep the large-scale circulation in hydrostatic and geostrophic balance, and it creates a favorable environment for enhanced rainfall anomalies along the mei-yu band (Figs. 3a,b). In the postperiod, in contrast, both the anomalous vorticity advection and temperature advection are weak at approximately $35^{\circ} \mathrm{N}$ (Figs. 8c,d). Therefore, the vertical motion induced by dry dynamics is weak, which results in weak rainfall anomalies along the mei-yu band (Figs. 3c,d).

\section{d. Role of the energy conversion from basic flow}

Kosaka and Nakamura $(2006,2010)$ suggested that the $\mathrm{PJ}$ pattern is a moist dynamical mode inherent in the basic flow over the WNP. On one hand, the PJ pattern excited by convection near the Philippines can extract eddy energy efficiently from the basic flow via barotropic and baroclinic processes. On the other hand, it can reinforce the anomalous convection by modulating anomalous water vapor convergence and vertical motion and further strengthen the PJ pattern amplitude. Therefore, it is necessary to investigate whether the energy conversion 
TABLE 1. Time scales (day) that the eddy energy associated with the PJ pattern could be replenished through a particular energy conversion process in the preperiod and postperiod. Five energy conversion processes are evaluated (refer to the text for definitions). The eddy energy and conversion terms were integrated horizontally over $\left(5^{\circ}-85^{\circ} \mathrm{N}, 0^{\circ}-360^{\circ}\right)$ and vertically from 1000 to $100 \mathrm{hPa}$.

\begin{tabular}{lcc}
\hline \hline Term & Preperiod (1979-98) & Postperiod (1999-2015) \\
\hline$\tau_{\mathrm{CK}}$ & -76.1 & 71.3 \\
$\tau_{\mathrm{CP}}$ & 10.6 & 12.2 \\
$\tau_{\mathrm{CQ}}$ & 6.1 & 2.7 \\
$\tau_{\text {Dry }}$ & 23.5 & 19.5 \\
$\tau_{\text {Total }}$ & 7.9 & 3.9 \\
\hline
\end{tabular}

from basic flow contributes to the observed structural changes of the PJ pattern.

To quantitatively estimate the efficiency of different energy conversion processes in maintaining the PJ pattern, the time scale $\tau$ of a certain PJ pattern-related energy conversion process was evaluated following Kosaka and Nakamura (2010). Five time scales are considered$\tau_{\mathrm{CK}}, \tau_{\mathrm{CP}}, \tau_{\mathrm{CQ}}, \tau_{\text {Dry }}$, and $\tau_{\text {Total }}$-which represent the time scale to gain energy by barotropic energy conversion $(\mathrm{CK})$, baroclinic energy conversion (CP), diabatic generation $(\mathrm{CQ})$, dry energy conversion $(\mathrm{CK}+\mathrm{CP})$, and total energy conversion $(\mathrm{CK}+\mathrm{CP}+\mathrm{CQ})$, respectively. See Kosaka and Nakamura (2010) for more details. Here, the eddy energy and conversion terms are integrated horizontally over $\left(5^{\circ}-85^{\circ} \mathrm{N}, 0^{\circ}-360^{\circ}\right)$ and vertically from 1000 to $100 \mathrm{hPa}$. The $\tau$ indicates the time that the spatially integrated PJ pattern-related eddy energy could be replenished through a particular energy conversion process. Here, one conversion process will be considered as an efficient fueling term for the PJ pattern if $\tau$ is shorter than a season (i.e., 92 days). The negative value indicates the conversion process actually acts as an energy sink and damps the pattern.

Table 1 shows time scales of the five terms in the preand postperiods. In the preperiod, both $\mathrm{CP}$ and $\mathrm{CQ}$ can maintain the PJ pattern efficiently, while $\mathrm{CK}$ tends to damp the pattern in a less efficient way. As a result, both the dry energy conversion and the total energy conversion are efficient to maintain the PJ pattern. In the postperiod, $\mathrm{CK}, \mathrm{CP}$, and $\mathrm{CQ}$ are all efficient to sustain the PJ pattern. Especially, CQ shows a surprisingly high efficiency that can replenish the available potential energy of the PJ pattern in less than 3 days. Although it remains somewhat doubtful that $\mathrm{CQ}$ can contribute to the maintenance of the PJ pattern in the extratropics because of the weak baroclinic-barotropic coupling in the postperiod (section $4 \mathrm{~b}$ ), the results in Table 1 do suggest that the energy conversion from the basic flow is efficient to maintain the PJ pattern in both subperiods. This result indicates that the energy conversion from the basic field to the PJ pattern is not likely responsible for the structural changes of the PJ pattern in the late 1990s.

\section{Discussion}

A remarkable finding of this study is the diminished barotropic structure in the midlatitudes and the weakened vertical coupling of the PJ pattern after the late 1990s (Fig. 4). Here, the definition of the PJ pattern is based on the EOF1 of the $850-\mathrm{hPa}$ relative vorticity as a result of the more prominent structure of the PJ pattern in the lower troposphere (Kawamura et al. 1996). One may ask whether these reported phenomena under this "bottom up" strategy is robust and reliable. To address this issue, similar analyses were performed under the "top down" strategy. That is, EOF analysis is applied to the $200-\mathrm{hPa}$ relative vorticity field in the same region as that used for the 850 -hPa relative vorticity $\left(0^{\circ}-60^{\circ} \mathrm{N}, 100^{\circ}-160^{\circ} \mathrm{E}\right)$, and different variables are then regressed onto the normalized $\mathrm{PC1}$ time series $\left(\mathrm{PC}_{200 \mathrm{hPa}}\right)$. Figure 9 shows the latitudealtitude pattern of the relative vorticity over the longitude band $\left(110^{\circ}-150^{\circ} \mathrm{E}\right)$ regressed onto $\mathrm{PC}_{200 \mathrm{hPa}}$. This figure is identical to that in Fig. 4 but is based on $\mathrm{PC}_{200 \mathrm{hPa}}$. In the preperiod, the relative vorticity regressed onto $\mathrm{PCl}_{200 \mathrm{ha}}$ clearly shows a baroclinic structure in the low latitudes and an equivalent barotropic structure in the mid- and high latitudes (Fig. 9a), which is very similar to those shown in Fig. 4a. The barotropic structure in the extratropics extends to $1000 \mathrm{hPa}$, indicating strong coupling of circulation between the upper and lower troposphere. In the postperiod, in contrast, only two barotropic centers in the midlatitudes are observed, and the baroclinic structure in the low latitudes disappears (Fig. 9b). Moreover, the
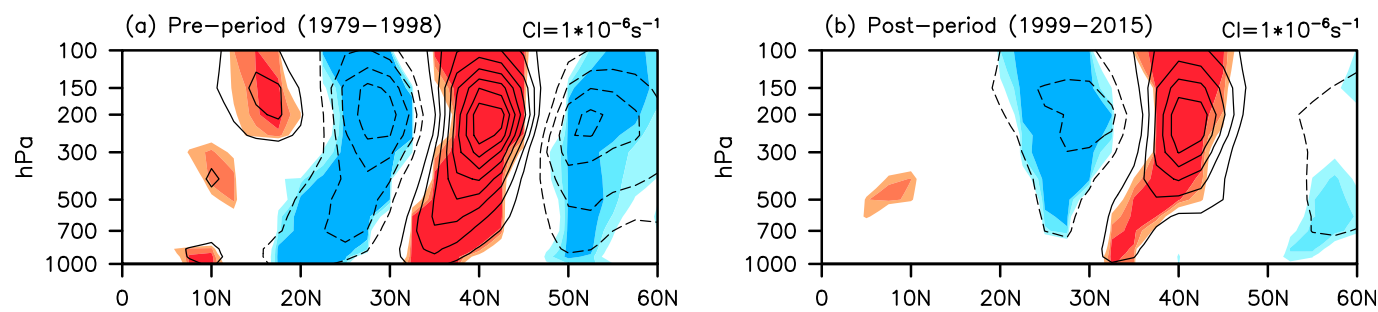

FIG. 9. As in Fig. 4, but regressed onto the normalized $\mathrm{PCl}_{200 \mathrm{hPa}}$. 
two barotropic centers in the extratropics cannot extend into the lower troposphere (Fig. 9b) as in the preperiod (Fig. 9a). These results suggest that the leading uppertropospheric variability over the East Asia-NWP region is no longer related to the convection-induced baroclinic pattern over the subtropical WNP in the postperiod, confirming the robustness of the results reported in sections 3 .

The PJ pattern was traditionally regarded as a dipolar teleconnection that is most prominent in the lower troposphere (Nitta 1987; Huang and Li 1987). However, the results shown in this study suggest that it may be more appropriate and insightful to regard the PJ pattern as a three-dimensional pattern that includes baroclinic structure in the low latitudes and barotropic structure in the mid- and high latitudes. The structures in both the lower and upper troposphere are important because the dipolar structure in the lower troposphere is important to alter the moisture convergence, while the zonally elongated structure in the upper troposphere is important to alter the vertical motion. This resultant moist dynamical feedback plays an important role in the self-maintenance of the PJ pattern (Kosaka and Nakamura 2006, 2010). Therefore, it may be necessary to revisit the definition of the PJ pattern to consider the three-dimensional structure of the PJ pattern in the future studies.

Another issue is why the PJ pattern-related convection and climatological variability of the convection center around the Philippines shift eastward in the postperiod. This may be understood from two aspects. On one hand, the eastward shift may be related to the eastward retreatment of the climatological subtropical high over WNP in the postperiod (Fig. 10), whose location may anchor the convection variability center (Yang et al. 2017). The Pacific SST pattern switched to negative Pacific decadal oscillation (PDO; Mantua et al. 1997) like in the late 1990s. The resultant cooling in the tropical eastern Pacific and warming in the tropical western Pacific can help to strengthen the Walker circulation (L'Heureux et al. 2013) and enhance the convection activity in the western Pacific (Zhang et al. 2016). Therefore, the latent heating is enhanced in the WNP, facilitating the eastward retreatment of subtropical high resulting from Sverdrup vorticity balance (Liu et al. 2001; Zhou et al. 2009). On the other hand, the eastward shift of the PJ pattern-related convection may be caused by the shift of the associated tropical SST forcing (Chen and Zhou 2014; Yim et al. 2014). Figure 11 presents the evolutions of SST anomalies associated with the PJ index in the preperiod (left panel) and the postperiod (right panel), which show distinct differences. The PJ pattern is related to the decaying phase of the canonical eastern Pacific ENSO before the late 1990s (Figs. 11a-e) and to the developing phase of

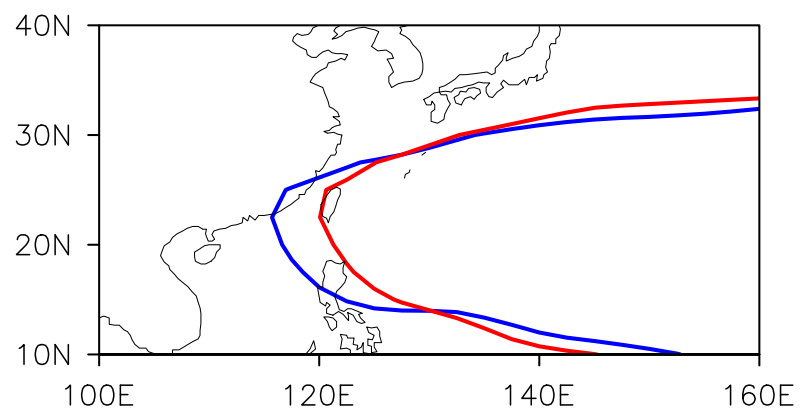

FIG. 10. Climatological summer mean 500-hPa western Pacific subtropical high (indicated by 5870 -gpm contour) during the preperiod (blue line) and postperiod (red line).

the central Pacific ENSO (Ashok et al. 2007) after that (Figs. 11f-j), consistent with Yim et al. (2008). If we focus on summer, when the PJ pattern is observed, we could see that the warm SST anomalies in the Indian Ocean are weakened and those in the eastern Maritime Continent are enhanced in the postperiod (Figs. 11c,h). This shift of SST anomalies suggests that SST forcing of the PJ pattern shifts eastward, consistent with Chen and Zhou (2014), who investigated the decadal changes in the periodicity of the PJ pattern in the mid-1990s (see their Figs. 7a,b). Further studies are needed to validate the aforementioned two hypotheses.

\section{Conclusions}

Based on several reanalysis and observational datasets, this study reveals that the PJ pattern, the dominant summertime teleconnection over East Asia, experienced significant structural changes in the late 1990s. In the preperiod (1979-98), the PJ pattern features a meridional dipole over the WNP in the lower troposphere (Fig. 2a), and a baroclinic structure in the subtropics and an equivalent barotropic structure in the extratropics (Fig. 4a), consistent with those reported in previous studies (e.g., Kosaka and Nakamura 2006). In the postperiod (19992015), the PJ pattern shifts eastward by approximately $20^{\circ}$ (Fig. 2c). Meanwhile, although its baroclininc structure in the subtropics remains almost unchanged, its barotropic structure in the extratropics is remarkably weakened (Fig. 4b). As a result, the influence of the PJ pattern on the mei-yu rainfall in the postperiod is diminished compared with the preperiod (Figs. 3c,d).

These observed changes in the PJ pattern can be explained from three aspects. First, the place where the PJ pattern-related diabatic heating released around the Philippines is located over approximately $\left(10^{\circ}-20^{\circ} \mathrm{N}\right.$, $120^{\circ}-140^{\circ} \mathrm{E}$ ) in the preperiod (Figs. 3a,b) but is shifted eastward after the late 1990s (Figs. 3c,d). This eastward shift is also associated with an eastward shift of 

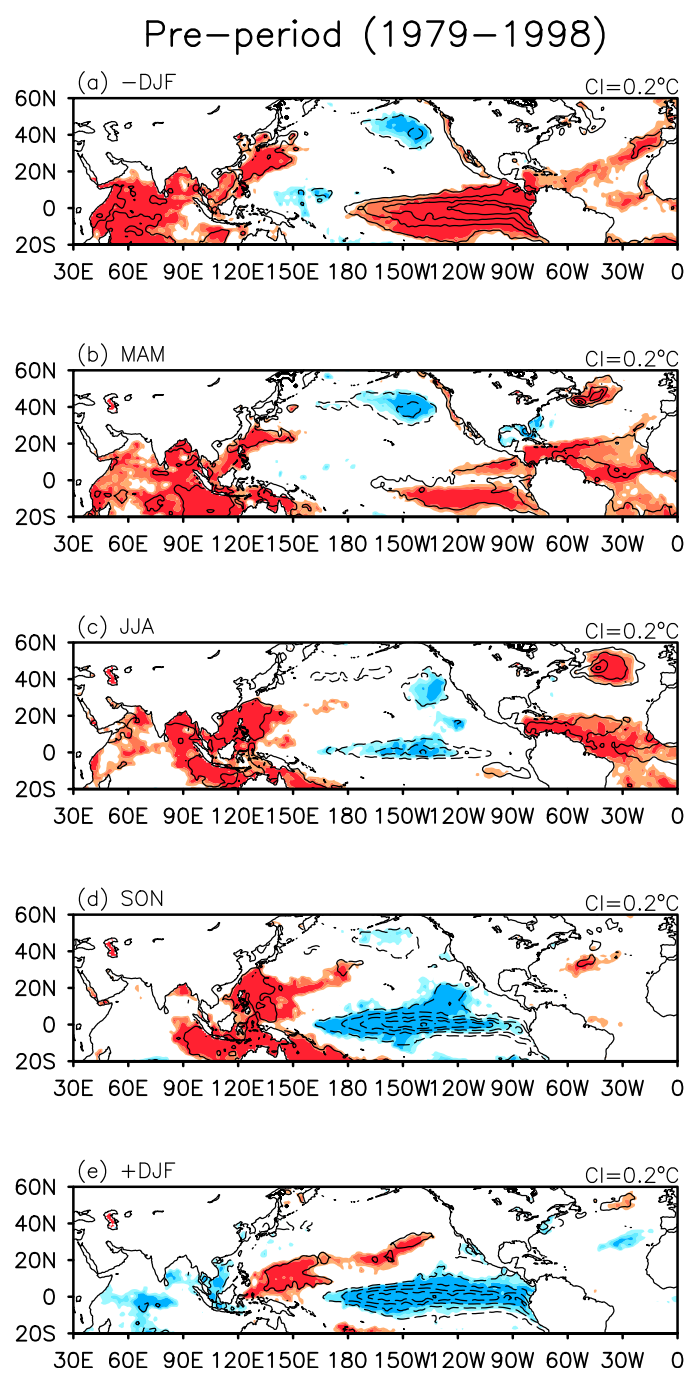

FIG. 11. Regression of SST onto the normalized PJ index in (a) the preceding winter, (b) the preceding spring, (c) the simultaneous summer, (d) the following autumn, and (e) the following winter during the preperiod $\left(\mathrm{CI}=0.2^{\circ} \mathrm{C}\right)$. (f)-(j) As in (a)-(e), respectively, but for the postperiod. The three shadings indicate the $90 \%$, $95 \%$, and $98 \%$ confidence levels, respectively, based on a two-tailed Student's $t$ test.

climatological convection variability (Fig. 6). Consequently, this shift directly leads to the eastward movement of the PJ pattern in the postperiod. Second, when the PJ pattern-related convection over the subtropical WNP shifts eastward after the late 1990s, it moves into a region where the easterly shear of the background zonal wind is weak (Fig. 7). As a result, the thermally excited baroclinic disturbance over the subtropical WNP is less efficiently converted into barotropic disturbance and propagates into the extratropics. This is likely the main reason for the weakened intensity of extratropical barotropic structure of the PJ pattern after the late 1990s. Third, because of the weakened barotropic anomalies of the PJ pattern after the late 1990s, the PJ pattern-related rainfall along the mei-yu band is also weakened as a result
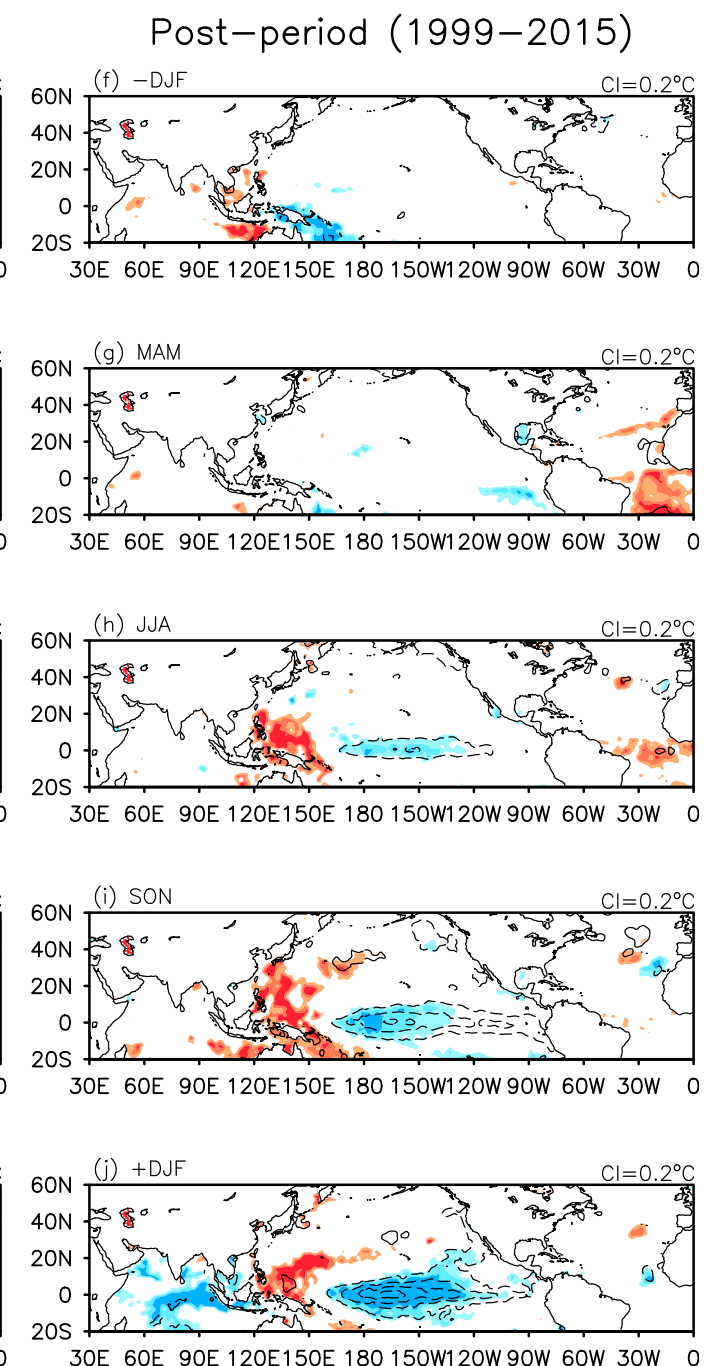

of the diminished vorticity advection and temperature advection (Fig. 8). Thus, the latent heating released by anomalous mei-yu rainfall is reduced, which may further contribute to the weakened barotropic anomalies of the PJ pattern in the extratropics. In addition to these three aspects, the possible role of energy conversion from the basic field to the PJ pattern is also examined. It reveals that the energy conversion efficiency remains similar in the two subperiods (Table 1), indicating the basic flow contributes little to the observed change of the PJ pattern.

In this study we found the PJ pattern experienced a structural change in the late 1990 s, which seems to be contradicted with some previous studies that suggest an interdecadal change of the PJ pattern or the East Asian summer monsoon in the early or mid-1990s (e.g., Chen 
and Zhou 2014; Yim et al. 2014). To check the robustness of our results, all the analyses were repeated by dividing the period into two subperiods from the early and mid1990s. It reveals that the structural difference of the PJ pattern between the pre- and postperiods is not as evident as reported in this study (not shown). These results suggest that the structure of the PJ pattern experienced a clear change not in the early or mid-1990s but in the late 1990s. Note that this study considers the changes of the three-dimensional structure of the PJ pattern in boreal summer (June-August), and that this is different from the changes of the periodicity of the PJ pattern (Chen and Zhou 2014) or the early summer (May and June) rainfall over East Asia (Yim et al. 2014). Hence, it is reasonable and understandable that the time shift reported in this study is slightly different from previous studies.

The results shown in this study may have more implications. The PJ pattern is one of the most important teleconnections to alter the East Asian summer climate (Kosaka et al. 2011; Huang et al. 2012), and it is also the bridge that transfers the influence of El Niño-Southern Oscillation (ENSO) to East Asia in ENSO's decaying summer (Zhang et al. 1996; Wang et al. 2000; Xie et al. 2009; Kosaka et al. 2013; Xie et al. 2016; Zhang et al. 2017; $\mathrm{Li}$ et al. 2017). In the presence of the eastward shift and the reduced amplitude of the barotropic structure of the PJ pattern, one may expect that the influences from the PJ pattern and possibly from ENSO on the summer climate over East Asia will diminish. These issues have been shown to some extent in our analysis (Figs. 3c,d, 11), but further related studies are still needed in the future.

Acknowledgments. We thank the three anonymous reviewers for their insightful comments and suggestions that led to improvement of the manuscript. We also thank Drs. Riyu Lu, Zhongda Lin, Yimin Liu, Chaofan $\mathrm{Li}$, Fei Liu, and Chongyin $\mathrm{Li}$ for their valuable comments and the stimulating discussions. This work was supported by the National Key Research and Development Program of China (2016YFA0600604), the National Natural Science Foundation of China (41721004), and the Science Foundation of Yunnan Province (2018FY001-18).

\section{REFERENCES}

Adler, R. F., and Coauthors, 2003: The Version-2 Global Precipitation Climatology Project (GPCP) monthly precipitation analysis (1979-present). J. Hydrometeor., 4, 1147-1167, https://doi.org/ 10.1175/1525-7541(2003)004<1147:TVGPCP > 2.0.CO;2.

Ashok, K., S. K. Behera, S. A. Rao, H. Weng, and T. Yamagata, 2007: El Niño Modoki and its possible teleconnection. J. Geophys. Res., 112, C11007, https://doi.org/10.1029/2006JC003798.

Chen, X., and T. Zhou, 2014: Relative role of tropical SST forcing in the 1990s periodicity change of the Pacific-Japan pattern interannual variability. J. Geophys. Res. Atmos., 119, $13043-$ 13 066, https://doi.org/10.1002/2014JD022064.

Dee, D. P., and Coauthors, 2011: The ERA-Interim reanalysis: Configuration and performance of the data assimilation system. Quart. J. Roy. Meteor. Soc., 137, 553-597, https://doi.org/10.1002/qj.828.

Ding, H., R. J. Greatbatch, M. Latif, W. Park, and R. Gerdes, 2013: Hindcast of the 1976/77 and 1998/99 climate shifts in the Pacific. J. Climate, 26, 7650-7661, https://doi.org/10.1175/JCLI-D-12-00626.1.

England, M. H., and Coauthors, 2014: Recent intensification of wind-driven circulation in the Pacific and the ongoing warming hiatus. Nat. Climate Change, 4, 222-227, https://doi.org/ 10.1038/nclimate2106.

Gong, H., L. Wang, W. Chen, R. Wu, G. Huang, and D. Nath, 2018: Diversity of the Pacific-Japan pattern among CMIP5 models: Role of SST anomalies and atmospheric mean flow. J. Climate, 31, 6857-6877, https://doi.org/10.1175/JCLI-D-17-0541.1.

Gu, W., L. Wang, Z.-Z. Hu, K. Hu, and Y. Li, 2018: Interannual variations of the first rainy season precipitation over South China. J. Climate, 31, 623-640, https://doi.org/10.1175/JCLI-D-17-0284.1.

Hirota, N., and M. Takahashi, 2012: A tripolar pattern as an internal mode of the East Asian summer monsoon. Climate Dyn., 39, 2219-2238, https://doi.org/10.1007/s00382-012-1416-y.

Holton, J. R., 2004: An Introduction to Dynamic Meteorology. Academic Press, 535 pp.

Hu, K., S.-P. Xie, and G. Huang, 2017: Orographically anchored El Niño effect on summer rainfall in central China. J. Climate, $\mathbf{3 0}$, $10037-10045$, https://doi.org/10.1175/JCLI-D-17-0312.1.

Huang, R. H., and W. J. Li, 1987: Influence of the heat source anomaly over the western tropical Pacific on the subtropical high over East Asia. Proc. Int. Conf. on the General Circulation of East Asia, Chengdu, China, Institute of Atmospheric Physics, Chinese Academy of Sciences, 40-51.

_- and L. Lu, 1989: Numerical simulation of the relationship between the anomaly of subtropical high over East Asia and the convective activities in the western tropical Pacific. Adv. Atmos. Sci., 6, 202-214, https://doi.org/10.1007/ BF02658016.

— , and Y. F. Wu, 1989: The influence of ENSO on the summer climate change in China and its mechanism. Adv. Atmos. Sci., 6, 21-32, https://doi.org/10.1007/BF02656915.

, and F. Y. Sun, 1992: Impacts of the tropical western Pacific on the East Asian summer monsoon. J. Meteor. Soc. Japan, 70, 243-256, https://doi.org/10.2151/jmsj1965.70.1B_243.

_ J. L. Chen, L. Wang, and Z. D. Lin, 2012: Characteristics, processes, and causes of the spatio-temporal variabilities of the East Asian monsoon system. Adv. Atmos. Sci., 29, 910942, https://doi.org/10.1007/s00376-012-2015-x.

Kanamitsu, M., W. Ebisuzaki, J. Woollen, S. K. Yang, J. J. Hnilo, M. Fiorino, and G. L. Potter, 2002: NCEP-DOE AMIP-II reanalysis (R-2). Bull. Amer. Meteor. Soc., 83, 1631-1643, https://doi.org/10.1175/BAMS-83-11-1631.

Kasahara, A., and P. L. da Silva Dias, 1986: Response of planetary waves to stationary tropical heating in a global atmosphere with meridional and vertical shear. J. Atmos. Sci., 43, 1893-1911, https:// doi.org/10.1175/1520-0469(1986)043<1893:ROPWTS>2.0.CO;2.

Kato, T., and Y. Matsuda, 1992: External mode induced by tropical heating in the basic flow with vertical shear and its propagation. J. Meteor. Soc. Japan, 70, 1057-1070, https://doi.org/ 10.2151/jmsj1965.70.6_1057.

Kawamura, R., T. Murakami, and B. Wang, 1996: Tropical and mid-latitude 45-day perturbations over the Western Pacific during the northern summer. J. Meteor. Soc. Japan, 74, 867890, https://doi.org/10.2151/jmsj1965.74.6_867. 
Kosaka, Y., and H. Nakamura, 2006: Structure and dynamics of the summertime Pacific-Japan teleconnection pattern. Quart. J. Roy. Meteor. Soc., 132, 2009-2030, https://doi.org/10.1256/qj.05.204.

- and - 2010: Mechanisms of meridional teleconnection observed between a summer monsoon system and a subtropical anticyclone. Part I: The Pacific-Japan pattern. J. Climate, 23, 5085-5108, https://doi.org/10.1175/ 2010JCLI3413.1.

— termodel diversity, and projected future changes over the summertime western North Pacific simulated in the CMIP3 models. J. Climate, 24, 3935-3955, https://doi.org/10.1175/ 2011JCLI3907.1.

— equatorial Pacific surface cooling. Nature, 501, 403-407, https://doi.org/10.1038/nature12534.

- - , and H. Nakamura, 2011: Dynamics of interannual variability in summer precipitation over East Asia. J. Climate, 24, 5435-5453, https://doi.org/10.1175/2011JCLI4099.1.

,,-- N.-C. Lau, and G. A. Vecchi, 2013: Origin of seasonal predictability for summer climate over the Northwestern Pacific. Proc. Natl. Acad. Sci. USA, 110, 7574-7579, https://doi. org/10.1073/pnas.1215582110.

Kurihara, K., and T. Tsuyuki, 1987: Development of the barotropic high around Japan and its association with Rossby wave-like propagations over the North Pacific: Analysis of August 1984. J. Meteor. Soc. Japan, 65, 237-246, https://doi.org/10.2151/ jmsj1965.65.2_237.

L'Heureux, M. L., S. Lee, and B. Lyon, 2013: Recent multidecadal strengthening of the Walker circulation across the tropical Pacific. Nat. Climate Change, 3, 571-576, https://doi.org/ 10.1038/nclimate1840.

Lau, K. M., and L. Peng, 1992: Dynamics of atmospheric teleconnections during the northern summer. J. Climate, 5, 140-158, https://doi.org/ 10.1175/1520-0442(1992)005<0140:DOATDT >2.0.CO;2.

Li, T., B. Wang, B. Wu, T. Zhou, C.-P. Chang, and R. Zhang, 2017: Theories on formation of an anomalous anticyclone in western North Pacific during El Niño: A review. J. Meteor. Res., 31, 987-1006, https://doi.org/10.1007/s13351-017-7147-6.

Liebmann, B., and C. A. Smith, 1996: Description of a complete (interpolated) OLR dataset. Bull. Amer. Meteor. Soc., 77, 1275-1277.

Lim, H., and C. P. Chang, 1986: Generation of internal-mode and external-mode motions from internal heating effects of vertical shear and damping. J. Atmos. Sci., 43, 948-957, https://doi. org/10.1175/1520-0469(1986)043<0948:GOIAEM>2.0.CO;2.

Lin, Z., F. Liu, B. Wang, R. Lu, and X. Qu, 2017: Southern European rainfall reshapes the early-summer circumglobal teleconnection after the late 1970s. Climate Dyn., 48, 3855-3868, https://doi.org/10.1007/s00382-016-3306-1.

Liu, Y., G. Wu, H. Liu, and P. Liu, 2001: Dynamical effects of condensation heating on the subtropical anticyclones in the Eastern Hemisphere. Climate Dyn., 17, 327-338, https://doi.org/10.1007/ s003820000117.

Lu, R., 2004: Associations among the components of the East Asian summer monsoon system in the meridional direction. J. Meteor. Soc. Japan, 82, 155-165, https://doi.org/10.2151/jmsj.82.155.

, and Z. Lin, 2009: Role of subtropical precipitation anomalies in maintaining the summertime meridional teleconnection over the western North Pacific and East Asia. J. Climate, 22, 2058-2072, https://doi.org/10.1175/2008JCLI2444.1.

Mantua, N. J., S. R. Hare, Y. Zhang, J. M. Wallace, and R. C. Francis, 1997: A Pacific interdecadal climate oscillation with impacts on salmon production. Bull. Amer. Meteor. Soc., 78 , 1069-1079, https://doi.org/10.1175/1520-0477(1997)078<1069: APICOW $>2.0 . C O ; 2$.

Nikaidou, Y., 1989: The PJ-like north-south oscillations found in 4month integrations of the global spectral model T42. J. Meteor. Soc. Japan, 67, 587-604, https://doi.org/10.2151/jmsj1965.67.4_587.

Nitta, T., 1986: Long-term variations of cloud amount in the western Pacific region. J. Meteor. Soc. Japan, 64, 373-390, https://doi.org/10.2151/jmsj1965.64.3_373.

, 1987: Convective activities in the tropical western Pacific and their impact on the Northern Hemisphere summer circulation. J. Meteor. Soc. Japan, 65, 373-390, https://doi.org/10.2151/ jmsj1965.65.3_373.

North, G. R., T. L. Bell, R. F. Cahalan, and F. J. Moeng, 1982: Sampling errors in the estimation of empirical orthogonal functions. Mon. Wea. Rev., 110, 699-706, https://doi.org/ 10.1175/1520-0493(1982)110<0699:SEITEO > 2.0.CO;2.

Rayner, N., D. E. Parker, E. B. Horton, C. K. Folland, L. V. Alexander, D. P. Rowell, E. C. Kent, and A. Kaplan, 2003: Global analyses of sea surface temperature, sea ice, and night marine air temperature since the late nineteenth century. J. Geophys. Res., 108, 4407, https://doi.org/10.1029/ 2002JD002670.

Sampe, T., and S. Xie, 2010: Large-scale dynamics of the meiyu-baiu rainband: Environmental forcing by the westerly jet. J. Climate, 23, 113-134, https://doi.org/10.1175/2009JCLI3128.1.

Sardeshmukh, P. D., and B. J. Hoskins, 1988: The generation of global rotational flow by steady idealized tropical divergence. J. Atmos. Sci., 45, 1228-1251, https://doi.org/10.1175/15200469(1988)045<1228:TGOGRF>2.0.CO;2.

Takaya, K., and H. Nakamura, 2001: A formulation of a phaseindependent wave-activity flux for stationary and migratory quasigeostrophic eddies on a zonally varying basic flow. J. Atmos. Sci., 58, 608-627, https://doi.org/10.1175/1520-0469 (2001)058<0608:AFOAPI $>2.0 . \mathrm{CO} ; 2$.

Tao, L., T. Li, Y.-H. Ke, and J.-W. Zhao, 2017: Causes of interannual and interdecadal variations of the summertime Pacific-Japan-like pattern over East Asia. J. Climate, 30, 8845-8864, https://doi.org/10.1175/JCLI-D-15-0817.1.

Tsuyuki, T., and K. Kurihara, 1989: Impact of convective activity in the western tropical Pacific on the East Asian summer circulation. J. Meteor. Soc. Japan, 67, 231-247, https://doi.org/ 10.2151/jmsj1965.67.2_231.

Wang, B., and X. Xie, 1996: Low-frequency equatorial waves in vertically sheared zonal flow. Part I: Stable waves. J. Atmos. Sci., 53, 449-467, https://doi.org/10.1175/1520-0469(1996) $053<0449$ :LFEWIV $>2.0$. CO 2 .

- R. Wu, and X. Fu, 2000: Pacific-East Asian teleconnection: How does ENSO affect East Asian climate? J. Climate, 13, 1517-1536, https://doi.org/10.1175/1520-0442(2000)013<1517: PEATHD $>2.0 . \mathrm{CO} ; 2$.

,-- , and K. M. Lau, 2001: Interannual variability of the Asian summer monsoon: Contrasts between the Indian and the western North Pacific-East Asian monsoons. J. Climate, 14, 4073-4090, https://doi.org/10.1175/1520-0442(2001)014<4073: IVOTAS $>2.0 . \mathrm{CO} ; 2$.

Wang, L., W. Chen, and R. Huang, 2007: Changes in the variability of North Pacific Oscillation around 1975/1976 and its relationship with East Asian winter climate. J. Geophys. Res., 112, D11110, https://doi.org/10.1029/2006JD008054.

- - W. Zhou, J. C. L. Chan, D. Barriopedro, and R. H. Huang, 2010: Effect of the climate shift around mid-1970s on the relationship between wintertime Ural blocking circulation 
and East Asian climate. Int. J. Climatol., 30, 153-158, https:// doi.org/10.1002/joc.1876.

— , P. Xu, W. Chen, and Y. Liu, 2017: Interdecadal variations of the Silk Road pattern. J. Climate, 30, 9915-9932, https://doi.org/ 10.1175/JCLI-D-17-0340.1.

Wu, B., T. Zhou, and T. Li, 2016: Impacts of the Pacific-Japan and circumglobal teleconnection patterns on the interdecadal variability of the East Asian summer monsoon. J. Climate, 29, 3253-3271, https://doi.org/10.1175/JCLI-D-15-0105.1.

Xie, S.-P., K. Hu, J. Hafner, H. Tokinaga, Y. Du, G. Huang, and T. Sampe, 2009: Indian Ocean capacitor effect on Indo-western Pacific climate during the summer following El Niño. J. Climate, 22, 730-747, https://doi.org/10.1175/2008JCLI2544.1.

_ , Y. Kosaka, Y. Du, K. M. Hu, J. Chowdary, and G. Huang, 2016: Indo-western Pacific ocean capacitor and coherent climate anomalies in post-ENSO summer: A review. Adv. Atmos. Sci., 33, 411-432, https://doi.org/10.1007/s00376-015-5192-6.

Yang, R., T. Yun, and C. Jie, 2010: A mechanism for the interannual variation of the early summer East Asia-Pacific teleconnection wave train. Acta Meteor. Sin., 24, 452-458.

_ Z. Xie, and J. Cao, 2017: A dynamic index for the westward ridge point variability of the western Pacific subtropical high during summer. J. Climate, 30, 3325-3341, https://doi.org/ 10.1175/JCLI-D-16-0434.1.

—, J. Wang, T. Zhang, and S. He, 2018: Change in the relationship between the Australian summer monsoon circulation and boreal summer precipitation over Central China in the late 1990s. Meteor. Atmos. Phys., https://doi.org/10.1007/ s00703-017-0556-3, in press.

Yim, S. Y., J. G. Jhun, and S. W. Yeh, 2008: Decadal change in the relationship between east Asian-western North Pacific summer monsoons and ENSO in the mid-1990s. Geophys. Res. Lett., 35, L20711, https://doi.org/10.1029/2008GL035751.
B. Wang, and M. Kwon, 2014: Interdecadal change of the controlling mechanisms for East Asian early summer rainfall variation around the mid-1990s. Climate Dyn., 42, 1325-1333, https://doi.org/10.1007/s00382-013-1760-6.

Zhang, J.-Y., L. Wang, S. Yang, W. Chen, and J. Huangfu, 2016: Decadal changes of the wintertime tropical tropospheric temperature and their influences on the extratropical climate. Sci. Bull., 61, 737-744, https://doi.org/10.1007/ s11434-016-1054-6.

Zhang, R., 2015: Changes in East Asian summer monsoon and summer rainfall over eastern China during recent decades. Sci. Bull., 60, 1222-1224, https://doi.org/10.1007/s11434015-0824-x.

— - A. Sumi, and M. Kimoto, 1996: Impact of El Niño on the East Asian monsoon: A diagnostic study of the '86/87 and ' $91 / 92$ events. J. Meteor. Soc. Japan, 74, 49-62, https://doi.org/ 10.2151/jmsj1965.74.1_49.

,-- , and — 1999: A diagnostic study of the impact of El Niño on the precipitation in China. Adv. Atmos. Sci., 16, 229241, https://doi.org/10.1007/BF02973084.

_ Q. Y. Min, and J. Z. Su, 2017: Impact of El Niño on atmospheric circulations over East Asia and rainfall in China: Role of the anomalous western North Pacific anticyclone. Sci. China Earth Sci., 60, 1124-1132, https://doi.org/10.1007/ s11430-016-9026-x.

Zhao, G. J., G. Huang, R. G. Wu, W. C. Tao, H. N. Gong, X. Qu, and K. M. Hu, 2015: A new upper-level circulation index for the East Asian summer monsoon variability. J. Climate, 28, 9977-9996, https://doi.org/10.1175/JCLID-15-0272.1.

Zhou, T., and Coauthors, 2009: Why the western Pacific subtropical high has extended westward since the late 1970s. J. Climate, 22, 2199-2215, https://doi.org/10.1175/2008JCLI2527.1. 